\title{
Expanding the structural diversity of biologically active spirocyclohexadienones from Morita-Baylis-Hillman (MBH) adducts
}

\section{Lucimara J. Martins ${ }^{1}$, Bruno R. Vilachã Ferreira ${ }^{2}$, Marcelo Lancellotti ${ }^{3}$ and Fernando Coelho".}

\section{State University of Campinas - Chemistry Institute - Dept. Organic Chemistry - PO Box 6154 - Campinas-SP, 13084971 Brazil 1/ucmartins@iqm.unicamp.br}

Keywords: Morita-Baylis-Hillman, Spirocyclohexadienones, Structural Diversity

\section{INTRODUCTION}

Recently we have developed a new strategy for the synthesis of spirocyclohexadienones. ${ }^{1,2}$

Due to the antibacterial and antiproliferative activities showed by these compounds it was necessary to obtain a set of them with great structural diversity in order to establish a broad biological profile of these compounds. In this comunication we describe some modifications in our original sequence which allowed the preparation of new spirocyclohexadienones.

\section{RESULTS AND DISCUSSION}

Searching to establish a SAR profile, we need to prepare saturated spirocyclohexadienone, represented by compound 3 . So, Heck adduct 1 was reduced in the presence of $\mathrm{NaBH}_{4}$ to give a mixture of diastereisomeric alcohols in $98 \%$ yield. The mixture was treated with PIFA at low temperature to afford 3 as a mixture of non separable diastereoisomers (1:3) in 65\% yield (Scheme 1).

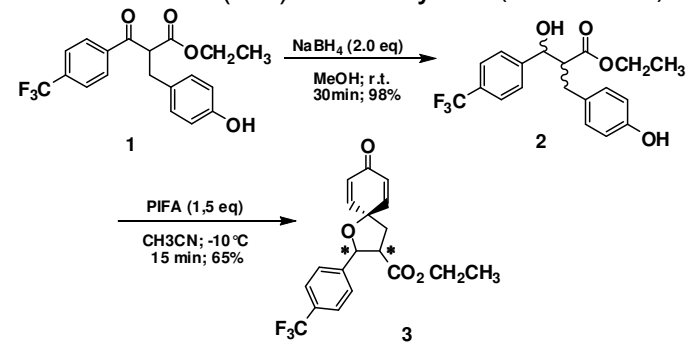

Scheme 1. Synthetic steps to obtain the spiro 3.

The previously synthezised spirocyclohexadienones were tested against some microorganisms. These compounds have showed the biological profile of some spirocyclohexadienones was the spirocyclohexadienone a good anti-bacterial activity, however only against Gram-(+) strains. Searching to broaden the action of these spirocompounds, 5 was prepared by base hydrolysis of 4 ( $\mathrm{LiOH}-10 \mathrm{eq})$ under mild conditions, to gave acid $\mathbf{5}$ in $98 \%$ (Scheme 2).

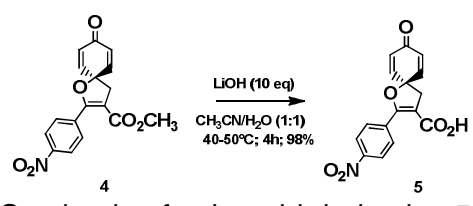

Scheme 2. Synthesis of spiroacid derivative 5.

Starting from $\mathrm{MBH}$ adducts prepared with acrylonitrile, spirocompounds as $\mathbf{6}$ were also obtained (Figure 1).

Spirocompounds having aromatic rings substituted by electrodonating have showed a remarkable antibacterial profile. Based on that experimental observation spiro compound 7 has been prepared (Figure 1).

Gimnastatin $\mathrm{I}^{4}$ is a natural compounds isolated from a japonese sponge. This compound has a very good antiproliferative profile. Based on the structural similarity, we synthesized spiro compound $\mathbf{8}$, from the $\mathrm{MBH}$ adduct derived from decanal (Scheme 3 ).

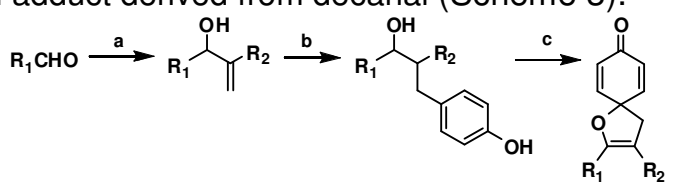

Reagentes e condições: a. alceno ativado, DABCO, r.t., 168h; b. lodofenol (1,2 eq.), $\mathrm{Et}_{3} \mathrm{~N}$ (2,8 eq.), catalisador de Nàjera (0,5 mol\%). DMF, $110^{\circ} \mathrm{C}, 3 \mathrm{~h}$; c. PIFA (1,5 eq.), CH3CN, Compound

poun

6

$\mathbf{R}_{1}$

acrylonitrile

Ethyl acrylate

Methyl acrylate

$\begin{array}{cc}\mathbf{R}_{\mathbf{2}} & \text { Yield (\%) } \\ \text { 3-OMePh- } & 35 \\ \text { 3,4,5-triOMePh- } & 40 \\ \mathrm{CH}_{3}\left(\mathrm{CH}_{2}\right)_{8^{-}} & 16\end{array}$

Scheme 3 Synthetic steps to obtain the spiros 6, 7, and 8.

\section{CONCLUSION}

A set of biologically active spirocyclohexadienones has been synthesized using a direct approach

\section{ACKNOWLEDGEMENTS}

UNICAMP, FAPESP, CNPq.

\section{REFERENCES}

${ }^{1}$ Ferreira. B. R. V.; Pirovani, R. V.; Souza-Filho, L. G.; Coelho, F.; Tetrahedron, 2009, 65, 7712. ${ }^{2}$ (a) Pirovani, R. V.; Ferreira, B. R. V,; Coelho, F. Synlett, 2009, 2333. ${ }^{3}$ Zhdankin, V. V.; Stang, P. J. Chem. Rev. 2008, 108, 5299. "Amagata, T.; Takigawa, K.; Minoura, K.; Numata, A. Heterocycles 2010, 81, 897. 